\title{
Comparative analysis of real-time precise point positioning zenith total delay estimates
}

\author{
F. Ahmed $\cdot$ P. Václavovic $\cdot$ F. N. Teferle $\cdot$ \\ J. Douša $\cdot$ R. Bingley $\cdot$ D. Laurichesse
}

Received: 17 February 2014/ Accepted: 10 November 2014/Published online: 25 November 2014

(C) The Author(s) 2014. This article is published with open access at Springerlink.com

\begin{abstract}
The continuous evolution of global navigation satellite systems (GNSS) meteorology has led to an increased use of associated observations for operational modern low-latency numerical weather prediction (NWP) models, which assimilate GNSS-derived zenith total delay (ZTD) estimates. The development of NWP models with faster assimilation cycles, e.g., 1-h assimilation cycle in the rapid update cycle NWP model, has increased the interest of the meteorological community toward sub-hour ZTD estimates. The suitability of real-time ZTD estimates obtained from three different precise point positioning software packages has been assessed by comparing them with the state-of-the-art IGS final troposphere product as well as collocated radiosonde (RS) observations. The ZTD estimates obtained by BNC2.7 show a mean bias of $0.21 \mathrm{~cm}$, and those obtained by the G-Nut/Tefnut software library show a mean bias of $1.09 \mathrm{~cm}$ to the IGS final troposphere product. In comparison with the RS-based ZTD, the BNC2.7 solutions show mean biases between 1 and $2 \mathrm{~cm}$, whereas the G-Nut/Tefnut solutions show mean biases between 2 and $3 \mathrm{~cm}$ with the RS-based ZTD, and the
\end{abstract}

F. Ahmed $(\bowtie) \cdot$ F. N. Teferle

Geophysics Laboratory, University of Luxembourg,

Luxembourg, Luxembourg

e-mail: furqan.ahmed@uni.lu

P. Václavovic · J. Douša

Geodetic Observatory Pecny, Research Institute of Geodesy,

Topography and Cartography, Prague, Czech Republic

R. Bingley

Nottingham Geospatial Institute, University of Nottingham,

Nottingham, UK

D. Laurichesse

Centre National d'Etudes Spatiales, Paris, France ambiguity float and ambiguity fixed solutions obtained by PPP-Wizard have mean biases between 6 and $7 \mathrm{~cm}$ with the references. The large biases in the time series from PPP-Wizard are due to the fact that this software has been developed for kinematic applications and hence does not apply receiver antenna eccentricity and phase center offset (PCO) corrections on the observations. Application of the eccentricity and $\mathrm{PCO}$ corrections to the a priori coordinates has resulted in a $66 \%$ reduction of bias in the PPP-Wizard solutions. The biases are found to be stable over the whole period of the comparison, which are criteria (rather than the magnitude of the bias) for the suitability of ZTD estimates for use in NWP nowcasting. A millimeter-level impact on the ZTD estimates has also been observed in relation to ambiguity resolution. As a result of a comparison with the established user requirements for NWP nowcasting, it was found that both the G-Nut/Tefnut solutions and one of the BNC2.7 solutions meet the threshold requirements, whereas one of the BNC2.7 solution and both the PPPWizard solutions currently exceed this threshold.

Keywords GPS - GNSS - Real time - Zenith total delay · Precise point positioning $\cdot$ Ambiguity resolution

\section{Introduction}

The observations from Global Navigation Satellite System (GNSS) systems can be used to study the state of the troposphere at a given location and time by estimating the respective amount of zenith total delay (ZTD) and converting this to integrated water vapor (IWV) using surface meteorological data (Bevis et al. 1994). Both of these GNSS-derived tropospheric parameters (ZTD and IWV) can further be assimilated into numerical weather 
prediction (NWP) models having a positive impact on the quality of weather forecasts (Bennitt and Levick 2011; de Haan 2011; Gutman et al. 2004; Vedel et al. 2004). As of today, the global positioning system (GPS) is the most widely used GNSS in operational meteorology. However, research is ongoing for the inclusion of other GNSS in meteorological applications. Therefore, in the following text, the term GNSS would refer to GPS unless otherwise stated.

Over the last decade, a number of international research projects and programs in Europe (Elgered 2001; Huang et al. 2003), North America (Smith et al. 2007) and Asia (Iwabuchi et al. 2000) have investigated the use of GNSSderived near real-time (NRT) ZTD estimates in NWP models. Since 2005, the EUMETNET EIG GNSS Water Vapor Program (E-GVAP) enables various analysis centers across Europe to submit their NRT ZTD estimates for assimilation into the NWP models of the partner meteorological institutions (Vedel et al. 2013). In late 2012, another European project "COST Action ES1206: Advanced GNSS Tropospheric Products for Monitoring Severe Weather Events and Climate (GNSS4SWEC)" (Jones et al. 2014) was approved to investigate GNSS meteorology further in the light of modern challenges and developments.

As of today, the NRT ZTD estimates are assimilated into local-, regional- and global-scale NWP models that are run with 3-6 h update cycles and produce long-term (up to a few days) weather forecasts. However, with the developments of high update-rate NWP models, e.g., the rapid update cycle (RUC) (Benjamin et al. 2010) and the realtime meso-analysis high-resolution rapid refresh (RTMAHRRR) (Brian et al. 2014), and in order to use the ZTD estimates for NWP nowcasting and monitoring extreme short-term weather changes, it is desired to obtain them with a minimal latency of 10 or even 5 min while maintaining an accuracy of 5-30 mm (Offiler 2010).

The real-time (RT) transport of GNSS observational data and products is carried out in the formats specified by the Special Committee 104 (SC104) of the Radio Technical Commission for Maritime Services (RTCM) (http://www. rtcm.org/) using the Network Transport of RTCM via Internet Protocol (NTRIP) (Weber et al. 2006). Since December 2012, the real-time service (RTS) of the International GNSS Service (IGS) (Caissy et al. 2012; Dow et al. 2009) and its associated analysis centers are making RT orbit and clock products officially available to the GNSS community. These products include the broadcast ephemeris and the orbit and clock corrections. The IGS together with RTCM-SC104 has defined different formats for the dissemination of observation and correction data in RT. The format for observation data messages is called RTCM-3 and that for orbit and clock correction messages is called RTCM-SSR, where SSR stands for state space representation (Wübbena et al. 2005). The RTCM-SSR real-time streams are composed of various types of messages.

Using the RT data and products, ZTD can be estimated in RT, but different strategies result in different accuracies of the ZTD estimates. The availability of orbit and clock products in RT triggers the possibility to perform precise point positioning (PPP) (Zumberge et al. 1997) in RT. Although both the double-differenced (DD) and PPP processing strategies can be implemented in RT, PPP is highly suitable for RT processing due to being computationally more efficient.

Various error sources can affect the accuracy of the GNSS-derived ZTD estimates. In PPP processing, the ZTD is more sensitive to the radial component of the orbit error, whereas in DD processing, it is more sensitive to the tangential component of the orbit error (Douša 2012). Although the first-order ionospheric delay is eliminated using the linear combination of the measurements from two different carriers, there remains still a smaller effect from the higher-order terms of the ionospheric delay, especially during the times of high solar activity. There is a linear dependency between the daily mean of the total electron content (TEC) unit and the estimated vertical position (Fritsche et al. 2005). If the error in ZTD is approximated as one-third of the vertical position error (Hill et al. 2009), it would mean that an increase of the TEC unit from 25 to 175 will result in a ZTD error ranging from 0.6 to $4 \mathrm{~mm}$ if higher-order ionospheric corrections are not applied. Furthermore, errors in the a priori zenith hydrostatic delay (ZHD) caused by the use of inaccurate surface pressure values could result in an error of -0.1 to $-0.2 \mathrm{~mm} / \mathrm{hPa}$ in vertical position estimates (Tregoning and Herring 2006), and this could also lead to an error in the ZTD. Antennarelated errors, e.g., phase center offsets (PCO) and variations (PCV) and radome geometry, also lead to errors in the vertical position and the ZTD estimates. Byun and BarSever (2009) and Thomas et al. (2011) have shown that differences in the estimated ZTD with and without the PCV corrections may vary from 2 to $10 \mathrm{~mm}$. The effect of inaccurate or unaccounted PCOs may be even larger (up to few centimeters). The tropospheric mapping functions (MF), which are used to map the tropospheric delay from other angles (slant) to zenith, also have an elevationdependent effect on the corresponding ZTD, although the effect of the MF reduces with an increase in any elevation cut-off angle used for observations (Ning 2012).

Fixing of integer phase ambiguities enhances the precision of the position estimates. In the DD strategy, common errors are removed and it becomes easier to identify and fix such integer ambiguities. However, for un-differenced observations, it was not possible to fix the integer phase 
ambiguities until recently (Geng et al. 2010). Among others, the Centre National d'Etudes Spatiales (CNES) has developed strategies to fix integer ambiguities of un-differenced phase measurements by first fixing the difference between the ambiguities on the two carrier frequencies and then fixing the remaining ambiguity in a global network solution (Loyer et al. 2012). To date, only few studies have been performed to study the impact of ambiguity resolution on GNSS-based ZTD estimates in RT-PPP with some of them benefitting from software and products not necessarily available to the community (Shi and Gao 2012; Li et al. 2014).

We have evaluated the suitability of RT-PPP ZTD estimates for meteorological applications through a comparison with the IGS final troposphere product and collocated radiosonde (RS) observations. These estimates have been obtained by three different PPP software packages using RT orbit and clock products from the IGS RTS as well as from the individual analysis center CNES. The effect of integer ambiguity resolution on ZTD estimates has also been studied. All three software packages and products used are freely available.

The next sections describe the RT-PPP software packages, the RT data and products, and the reference solutions used in this study followed by results, discussion and conclusions.

\section{Real-time PPP systems}

The real-time processing for a selection of GNSS stations and time periods was simultaneously performed at the University of Luxembourg (UL) and the Geodetic Observatory Pecny (GOP). UL generated the solutions from BNC2.7 and PPP-Wizard, whereas GOP generated the solutions using the Tefnut application from their G-Nut software library.

The BKG Ntrip Client (BNC), developed by the Bundesamt für Kartographie und Geodäsie (BKG) (Weber and Mervart 2012), is capable of performing PPP in RT (RT-PPP). For this study, version 2.7 of the BNC has been used to perform RT-PPP using streams of code plus phase observations, the broadcast ephemeris and correction streams for satellite orbits and clocks. During the processing in BNC, these corrections from the RT streams are applied to the broadcast ephemeris. Along with the precise position estimates, the ZTD estimates can also be obtained as one of the outputs. The recent study by Yuan et al. (2014) is also based on this software package; however, they have modified it to implement some precise bias models such as ocean tide loading, receiver antenna PCV and computation of hydrostatic and wet mapping functions from Global Pressure and Temperature 2 (GPT2) model (Lagler et al. 2013).
To promote their ambiguity-fixing strategy, CNES developed the "Precise Point Positioning with Integer and Zero-difference Ambiguity Resolution Demonstrator (PPPWizard)" and started to produce a RT product containing corrections for integer ambiguity resolution, which can be used to fix ambiguities in RT-PPP mode (Laurichesse et al. 2009, Laurichesse 2011). Similar to BNC2.7, the PPPWizard was not developed with this particular application of RT GNSS meteorology in mind.

The G-Nut software library (Václavovic et al. 2013) has been developed at the Geodetic Observatory Pecny (GOP) since 2011 in order to support development of high-accuracy GNSS analysis. Several end user applications have been derived for meteorology and climatology (Tefnut), geodesy and seismology (Geb) and GNSS quality checking (Anubis). We have used the G-Nut/Tefnut software, which is capable of estimating GNSS tropospheric parameters in RT, NRT and post-processing modes (Douša and Vaclavovic 2014).

All the above-mentioned software packages use a Kalman filter. The configuration and characteristics of the software packages used in this study are shown in Table 1. For the BNC2.7 and PPP-Wizard solutions, the a priori coordinates of the stations were computed by a 20-day average of coordinates obtained using PPP with the Bernese GPS Software 5.0 (BSW50) (Dach et al. 2007). The G-Nut/Tefnut does not need a priori coordinates; however, if precise station coordinates are available, they can be introduced into the processing as a priori values. In this campaign, G-Nut/Tefnut was used without introducing a priori coordinates. During the RT data processing, BNC2.7 computed the receiver coordinates (unconstrained) in every epoch, whereas the version of PPP-Wizard used for this study did not estimate the receiver coordinates in order to reduce the number of unknown parameters. Hence, in the PPP-Wizard solution, the coordinates were fixed to the values provided a priori and the ZTD was estimated every $5 \mathrm{~s}$. The G-Nut/Tefnut software applied simultaneous coordinate and ZTD estimations. The former were tightly constrained to remain stable over time, while the latter were constrained loosely to optimally balance between stable and reliable tropospheric parameter estimates.

The convergence time of the RT-PPP solutions (coordinates and ZTD) is generally between 20 and $60 \mathrm{~min}$ depending among others on the quality of the station data and satellite constellation if no precise a priori coordinates are provided. However, as mentioned above, for PPPWizard and BNC2.7, the a priori coordinates were provided, and hence, the convergence time was not significant. For G-Nut/Tefnut, the results were filtered to include only the epochs after the convergence time.

The software packages BNC2.7 and PPP-Wizard are meant for RT and kinematic applications and therefore do 
Table 1 Configuration of the software packages used in this study

\begin{tabular}{|c|c|c|c|}
\hline Software & BNC2.7 & PPP-Wizard & G-Nut/Tefnut \\
\hline Update cycle & Real time & Real time & Real time \\
\hline Output interval & $1 \mathrm{~s}$ & $5 \mathrm{~s}$ & $5 \mathrm{~s}$ \\
\hline GNSS used & GPS & GPS & GPS \\
\hline Strategy & PPP & PPP & PPP \\
\hline $\begin{array}{l}\text { A priori ZHD } \\
\text { model }\end{array}$ & Saastamoinen & $\begin{array}{l}\text { Constant }(2.37 \\
\mathrm{m})\end{array}$ & Saastamoinen \\
\hline $\begin{array}{l}\text { Troposphere } \\
\text { mapping } \\
\text { function }\end{array}$ & $1 / \cos (\mathrm{z})$ & $\begin{array}{l}\text { GPS STANAG } \\
\text { (Chao's } \\
\text { coefficients) }\end{array}$ & GMF \\
\hline $\begin{array}{l}\text { Receiver PCV } \\
\text { correction }\end{array}$ & No & No & $\begin{array}{l}\text { Elevation- } \\
\text { dependent } \\
\text { only }\end{array}$ \\
\hline $\begin{array}{l}\text { Receiver PCO } \\
\text { correction }\end{array}$ & Yes & No & Yes \\
\hline $\begin{array}{l}\text { Satellite PCV } \\
\text { correction }\end{array}$ & No & Yes & Yes \\
\hline $\begin{array}{l}\text { Satellite PCO } \\
\text { correction }\end{array}$ & $\mathrm{No}^{\mathrm{a}}$ & $\mathrm{No}^{\mathrm{a}}$ & $\mathrm{No}^{\mathrm{a}}$ \\
\hline $\begin{array}{c}\text { Coordinates } \\
\text { computed }\end{array}$ & Yes & No & Yes \\
\hline $\begin{array}{l}\text { Ocean tide } \\
\text { loading } \\
\text { correction }\end{array}$ & No & No & No \\
\hline $\begin{array}{l}\text { Input raw data } \\
\text { format }\end{array}$ & RTCM-3 & RTCM-3 & RTCM-3 \\
\hline $\begin{array}{l}\text { Input orbit/ } \\
\text { Clock } \\
\text { correction } \\
\text { format }\end{array}$ & RTCM-SSR & RTCM-SSR & RTCM-SSR \\
\hline $\begin{array}{l}\text { Input broadcast } \\
\text { ephemeris } \\
\text { format }\end{array}$ & RTCM-SSR & RTCM-SSR & RTCM-SSR \\
\hline $\begin{array}{l}\text { Ambiguity } \\
\text { resolution }\end{array}$ & No & Yes & No \\
\hline
\end{tabular}

a In the correction streams used, the satellite's position refers to the ionosphere free phase center of its antenna, and therefore, the satellite antenna PCO correction is not necessary

not employ the most precise bias models, e.g., ocean tide loading and higher-order ionospheric corrections. The G-Nut/Tefnut is, however, meant for tropospheric applications, but it is still undergoing some developments and lacks some precise bias models such as the ocean tide loading.

\section{Real-time data and products}

The network of GNSS stations selected for this study comprises 22 globally distributed IGS stations, which provide RT observation data (Fig. 1). Table 2 provides the relevant station information. A dataset containing RT-PPP ZTD estimates for these stations and a time period of
31 days (2013-04-18 to 2013-05-18) was obtained using the software packages listed in the previous section. Only GPS observations have been used in this study. Table 3 provides some characteristics of the RT product streams used for this study.

The first reference dataset used to compare the RT-PPP ZTD estimates is the IGS final troposphere product (hereafter termed IGFT) generated by the U.S. Naval Observatory (USNO) (Byram et al. 2011). The IGFT is based on the final IGS orbit and clock products and contains the ZTD estimates computed by processing 27-h observation window using PPP with BSW50 at an output sampling interval of $5 \mathrm{~min}$.

The second reference dataset consists of the ZTD estimates derived from the observations of RS (NCAS-BADC 2006) collocated with five selected GNSS stations. The ZHD and the zenith wet delay (ZWD) at the RS locations have been corrected for height differences (to the GNSS station height). The height correction on ZHD has been applied using the method described in Douša and Elias (2014), whereas the ZWD has been corrected for height using the method described in Gyori and Douša (2013). However, no correction has been applied for the horizontal separation between the GNSS station and the collocated RS. Table 4 shows the selection of the RS sites along with their horizontal and vertical distances to the respective GNSS stations. The ZTD from GNSS observations (at the five stations shown in Table 4) has then been compared with the ZTD from the corresponding RS.

The statistics for the comparisons have been computed using only the common epochs in the respective datasets. Considering the noise level in the RT-PPP ZTD estimates, we argue that the statistics computed over the one month give a good indication of the quality (precision and the stability of biases) of the estimates. However, we acknowledge that the seasonality of the IWV may have a small influence on the comparison between the GNSSderived and RS-based ZTD (Park et al. 2012), which cannot be seen using the one month period.

\section{Results}

This section provides the results of the comparisons. For brevity, we will below refer to the BNC2.7 solutions using the IGS01 products as $\mathrm{BN} 01$, the $\mathrm{BNC} 2.7$ solutions using the IGS02 products as BN02, the PPP-Wizard (ambiguity float) solutions as PWFL, the G-Nut/Tefnut solutions using IGS01 products as GN01, and the G-Nut/Tefnut solutions using IGS02 products as GN02. Table 5 gives an overview of the product streams and software used in each of the solutions. IGS01 and IGS02 (tested with BNC2.7 and G-Nut/Tefnut) streams contain single-epoch and Kalman 
Fig. 1 IGS real-time stations used in this study

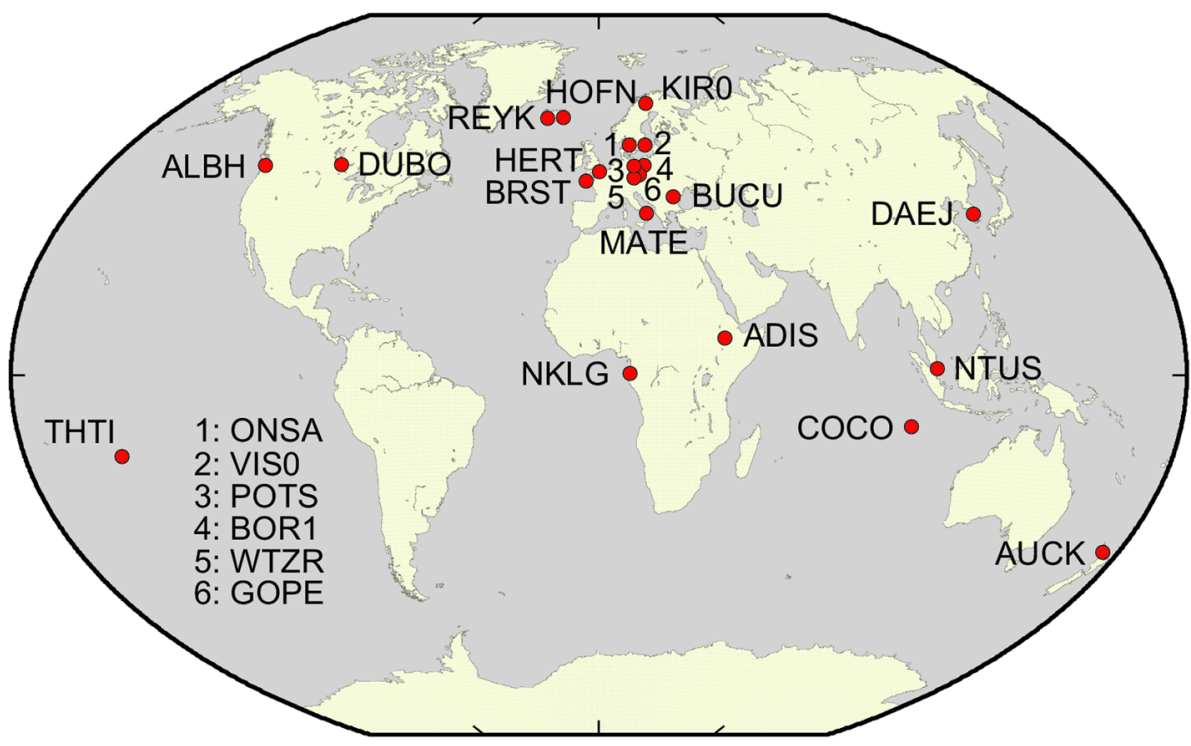

\begin{tabular}{|c|c|c|c|c|c|}
\hline Station & $\begin{array}{l}\text { IERS DOMES } \\
\text { number }\end{array}$ & Receiver type & Antenna and radome & & $\begin{array}{l}\text { ARP } \\
\text { eccentricity } \\
(\mathrm{Up})(\mathrm{m})\end{array}$ \\
\hline ADIS & 31502M001 & JPS LEGACY & TRM29659.00 & NONE & 0.0010 \\
\hline ALBH & 40129M003 & AOA BENCHMARK ACT & AOAD/M_T & SCIS & 0.1000 \\
\hline AUCK & 50209M001 & TRIMBLE NETR9 & TRM55971.00 & NONE & 0.0550 \\
\hline BOR1 & $12205 \mathrm{M} 002$ & TRIMBLE NETRS & AOAD/M_T & NONE & 0.0624 \\
\hline BRST & 10004M004 & TRIMBLE NETR9 & TRM57971.00 & NONE & 2.0431 \\
\hline BUCU & 11401M001 & LEICA GRX1200GGPRO & LEIAT504GG & LEIS & 0.0970 \\
\hline $\mathrm{COCO}$ & 50127M001 & TRIMBLE NETR8 & AOAD/M_T & NONE & 0.0040 \\
\hline DAEJ & 23902M002 & TRIMBLE NETRS & TRM59800.00 & SCIS & 0.0000 \\
\hline DUBO & 40137M001 & TPS NETG3 & AOAD/M_T & NONE & 0.1000 \\
\hline GOPE & $11502 \mathrm{M} 002$ & TPS NETG3 & TPSCR.G3 & TPSH & 0.1114 \\
\hline HERT & 13212M010 & LEICA GRX1200GGPRO & LEIAT504GG & NONE & 0.0000 \\
\hline HOFN & 10204M002 & LEICA GR25 & LEIAR25.R4 & LEIT & 0.0319 \\
\hline KIR0 & 10422M001 & JPS EGGDT & AOAD/M_T & OSOD & 0.0710 \\
\hline MATE & 12734M008 & LEICA GRX1200GGPRO & LEIAT504GG & NONE & 0.1010 \\
\hline NKLG & 32809M002 & TRIMBLE NETR9 & TRM59800.00 & SCIS & 3.0430 \\
\hline NTUS & 22601M001 & LEICA GRX1200GGPRO & LEIAT504GG & NONE & 0.0776 \\
\hline ONSA & 10402M004 & JPS E_GGD & AOAD/M_B & OSOD & 0.9950 \\
\hline POTS & 14106M003 & JAVAD TRE_G3TH DELTA & JAV_RINGANT_G3T & NONE & 0.1206 \\
\hline REYK & 10202M001 & LEICA GR25 & LEIAR25.R4 & LEIT & 0.0570 \\
\hline THTI & 92201M009 & TRIMBLE NETR8 & ASH701945E_M & NONE & 1.0470 \\
\hline VIS0 & 10423M001 & JPS EGGDT & AOAD/M_T & OSOD & 0.0710 \\
\hline WTZR & 14201M010 & LEICA GRX1200 + GNSS & LEIAR25.R3 & LEIT & 0.0710 \\
\hline
\end{tabular}

Table 2 Receiver and antenna information for IGS real-time stations used in this study ambiguity fixing only by keeping all other parameters in the fixed and float solutions consistent. Various technical problems, often related to data communication, compromise the transfer of real-time data and lead to gaps in the observation data, and hence, $100 \%$ of the data are not available in real time, which results in gaps in the RT-PPP 
Table 3 Real-time correction streams (http://rts.igs.org/products/, http://www.ppp-wizard.net/caster.html)

\begin{tabular}{llll}
\hline Stream & Content & Message types & Provider \\
\hline RTCM3EPH & Broadcast ephemeris & $1019,1020,1045$ & BKG \\
IGS01 & Orbit/clock correction (single-epoch solution) & 1059,1060 & ESA \\
IGS02 & Orbit/clock correction (Kalman filter combination) & $1057,1058,1059$ & BKG \\
CLK9B & Orbit/clock correction + corrections for integer ambiguity resolution & $1059,1060,1065,1066$ & CNES \\
\hline
\end{tabular}

Table 4 The selected radiosondes used for comparison

\begin{tabular}{llcl}
\hline $\begin{array}{l}\text { GNSS } \\
\text { station ID }\end{array}$ & $\begin{array}{l}\text { RS ID } \\
(\text { WMO })\end{array}$ & $\begin{array}{l}\text { Vertical separation } \\
(\text { GNSS-RS })(\mathrm{m})\end{array}$ & $\begin{array}{l}\text { Horizontal } \\
\text { separation }(\mathrm{km})\end{array}$ \\
\hline BUCU & 15420 & 53 & 4.0 \\
COCO & 96996 & -37 & 1.8 \\
HERT & 03882 & 32 & 4.0 \\
THTI & 91938 & 97 & 3.4 \\
VIS0 & 02591 & 33 & 2.0 \\
\hline
\end{tabular}

Table 5 Combinations of software package and product streams used in RT-PPP ZTD solutions

\begin{tabular}{llll}
\hline Solution & $\begin{array}{l}\text { Software } \\
\text { used }\end{array}$ & $\begin{array}{l}\text { Ephemeris } \\
\text { stream used }\end{array}$ & $\begin{array}{l}\text { Orbit/clock } \\
\text { product used }\end{array}$ \\
\hline BN01 & BNC2.7 & RTCM3EPH & IGS01 \\
BN02 & BNC2.7 & RTCM3EPH & IGS02 \\
PWFL & PPP-Wizard & RTCM3EPH & CLK9B \\
GN01 & G-Nut/Tefnut & RTCM3EPH & IGS01 \\
GN02 & G-Nut/Tefnut & RTCM3EPH & IGS02 \\
\hline
\end{tabular}

ZTD time series. In addition, some software packages provide more ZTD estimates than others based on the same input data. Table 6 shows the percentage of ZTD estimates obtained from each of the RT solutions for each station.

On average, the RT-PPP ZTD estimates were available for $78 \%$ of the selected time period from BNC27, $65 \%$ from PPP-Wizard, and $92 \%$ from G-Nut/Tefnut. The lower amount of available RT-PPP ZTD estimates from PPP-Wizard is due to missing data and product streams caused by a temporary network-related issue at UL from 2013-05-10 to 2013-05-18. Apart from the missing data, another reason for missing estimates for some epochs is that during the PPP convergence period, after a data gap, the ZTD estimates with large formal sigma are rejected.

Internal evaluation

For all the stations used in this study, the RT-PPP ZTD time series (not shown) obtained from all the solutions follow the same pattern. Figure 2 shows the time series of the difference between the RT-PPP ZTD estimates and the IGFT for these stations. The difference time series of
Table 6 Percentage of available RT-PPP ZTD epochs in different solutions

\begin{tabular}{llllll}
\hline Station & BN01 & BN02 & PWFL & GN01 & GN02 \\
\hline ADIS & 75 & 67 & 64 & 94 & 94 \\
ALBH & 97 & 95 & 55 & 95 & 95 \\
AUCK & 91 & 86 & 68 & 97 & 96 \\
BOR1 & 87 & 87 & 63 & 92 & 91 \\
BRST & 88 & 86 & 68 & 98 & 98 \\
BUCU & 98 & 98 & 68 & 85 & 84 \\
COCO & 60 & 86 & 65 & 95 & 95 \\
DAEJ & 96 & 96 & 67 & 96 & 96 \\
DUBO & 98 & 97 & 64 & 98 & 98 \\
GOPE & 92 & 92 & 64 & 93 & 93 \\
HERT & 93 & 91 & 68 & 98 & 98 \\
HOFN & 93 & 90 & 67 & 97 & 97 \\
KIR0 & 90 & 89 & 66 & 98 & 98 \\
MATE & 61 & 52 & 65 & 83 & 82 \\
NKLG & 52 & 53 & 69 & 99 & 99 \\
NTUS & 53 & 74 & 68 & 99 & 98 \\
ONSA & 88 & 86 & 66 & 99 & 98 \\
POTS & 56 & 52 & 68 & 98 & 98 \\
REYK & 73 & 77 & 61 & 91 & 91 \\
THTI & 61 & 47 & 68 & 99 & 99 \\
VIS0 & 94 & 95 & 68 & 84 & 84 \\
WTZR & 81 & 81 & 61 & 89 & 89 \\
\hline
\end{tabular}

PWFL solution in Fig. 2 has been plotted after removing the mean bias (considering the fact that the bias in the ZTD is removed before NWP assimilation, however, it is important that the bias is stable over time). The gap in the PWFL difference time series around day 11 for all 4 stations is due to a temporary interruption in the CLK9B product stream. For the station BOR1 (top right), the gap in the difference time series for all the RT solutions around day 3 is due to interruption of data stream from that station for this period. The gap in the GN01 and GN02 solution for the station BUCU (bottom left) around day 14 is due to an interruption in the data stream at that time at GOP.

The overall biases between the RT-PPP ZTD estimates from the individual RT solutions and the IGFT are shown in Table 7. It can be seen that the G-Nut/Tefnut solutions (GN01 and GN02) have a better stability (i.e., lower 

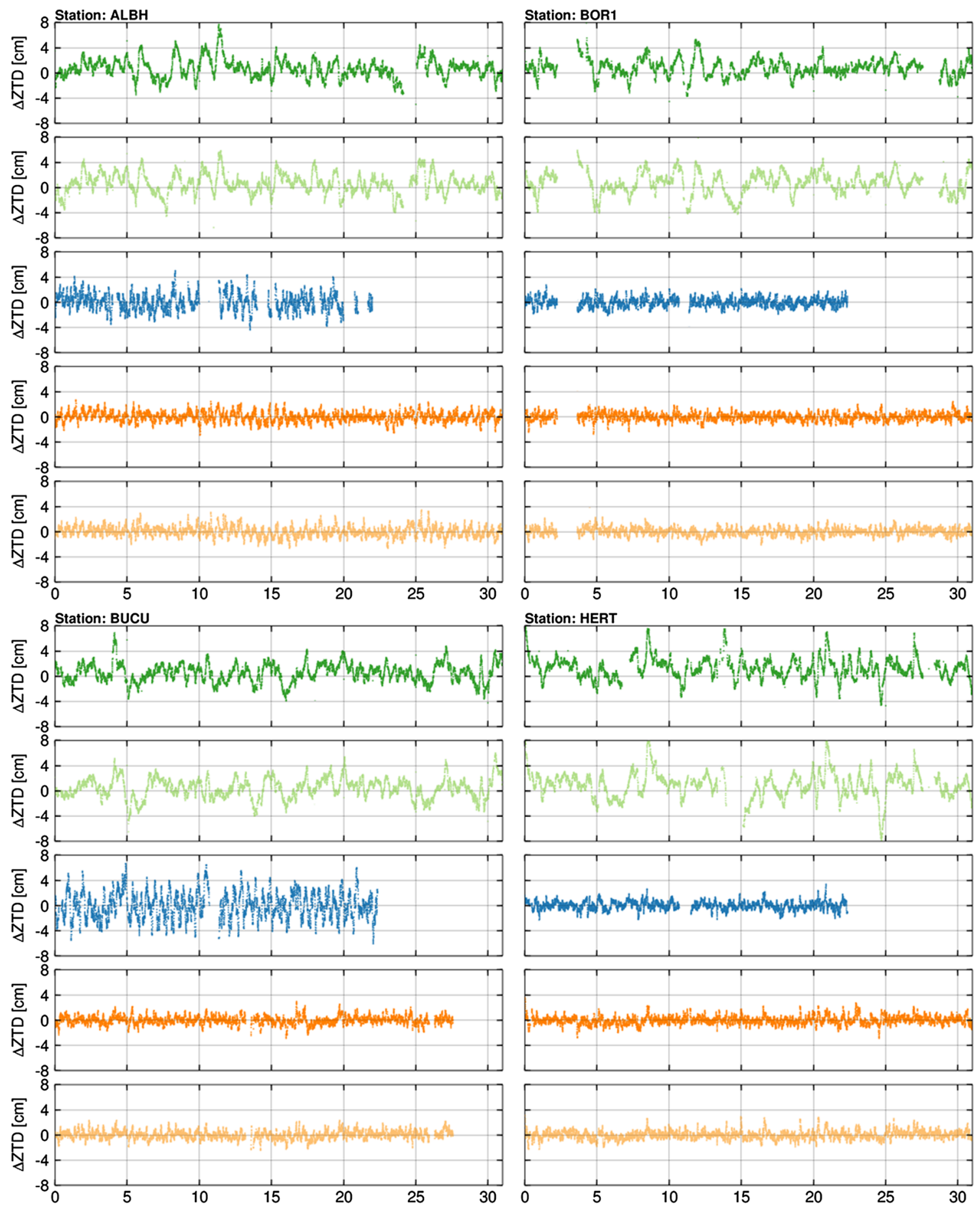

Fig. 2 Difference of RT-PPP ZTD estimates and IGFT for the stations ALBH, BOR1, BUCU and HERT in days since 2013-04-18 18:00:00UTC. Panels from the top: BN01, BN02, PWFL, GN01, GN02

standard deviation) of the mean bias as compared to the BNC2.7 solutions (BN01 and BN02). It should be noted that the two G-Nut/Tefnut solutions used the same strategy, software and data access, so any difference in results reflects the stability and reliability issues related to the applied products. Similarly, for the two BNC2.7 solutions, same processing strategy was used and the only difference was in the applied products. However, unlike the G-Nut/ Tefnut solutions, the mutual difference (in terms of bias) between the two BNC2.7 solutions is relatively larger. One possible reason for the lower bias in $\mathrm{BNO} 2$ as compared to that in BN01 could be the use of a Kalman Filter combination orbit/clock correction stream (IGS02) rather than a correction stream with single-epoch solution (IGS01) as in 
Table 7 Biases in RT-PPP ZTD solutions to IGFT

\begin{tabular}{lllc}
\hline Solution & Mean $(\mathrm{cm})$ & STD $(\mathrm{cm})$ & RMS $(\mathrm{cm})$ \\
\hline BN01 & 3.17 & 4.61 & 6.04 \\
BN02 & 0.21 & 2.72 & 2.92 \\
PWFL & 6.81 & 2.42 & 14.96 \\
GN01 & 1.16 & 0.82 & 1.43 \\
GN02 & 1.09 & 0.80 & 1.38 \\
\hline
\end{tabular}

BN01. The RMS of the difference between the RT-PPP ZTD from the BNC software and that from the IGFT as shown by Yuan et al. 2014 is lower than that found in this study, and this is because of the fact that they have implemented ocean tide loading corrections, improved mapping function and receiver antenna PCV correction in their version of BNC. The PPP-Wizard's ambiguity float solution (PWFL) has the largest mean bias, which is a consequence of the fact that the PPP-Wizard currently does not allow the application of antenna up eccentricity (height) and receiver antenna phase center models for offsets and variations, hence resulting in a mismatch between the constrained coordinates of the survey marker and the ZTD estimation at the antenna phase center. Table 8 shows the station-wise biases in PWFL with respect to the up eccentricities of the antenna ARP. However, for the assimilation into NWP models, it can be argued that the standard deviation of the ZTD is of more importance than the bias, because any station-specific biases are corrected for during the screening process before the assimilation. Also, aforementioned mean biases of the RT-PPP ZTD solutions (calculated over all stations) have less significance than that of the standard deviations because the biases vary with location and characteristics of the station.

As mentioned earlier, the PPP-Wizard is capable of resolving integer ambiguities in RT-PPP. In order to study the effect of integer ambiguity resolution on the RT-PPP ZTD estimates, another RT solution for the same stations and time period as above was obtained using PPP-Wizard with the ambiguity resolution feature. We term this solution as PWFX. Keeping in view the time needed for ambiguity convergence, only those epochs $(\approx 40 \%$ of the total) from PWFX have been included in the evaluation for which the number of fixed ambiguities is $\geq 4$. The difference between the RT-PPP ZTD of PWFL and PWFX solutions was found to be $0.61 \pm 4.66 \mathrm{~cm}$ with an RMS of $4.93 \mathrm{~cm}$. The observed impact of ambiguity resolution on ZTD is approximately $6 \mathrm{~mm}$, which compares well to, e.g., the $20 \%$ (4-5 mm) impact observed by Geng et al. (2009). The recent study by Li et al. (2014), which is based on their in-house software and products, also reported on the insignificant differences between the RT-PPP float and
Table 8 Station-wise mean bias in PWFL and the ARP UP eccentricity

\begin{tabular}{lrc}
\hline Station & ARP eccentricity $(U P)(\mathrm{cm})$ & PWFL bias $(\mathrm{cm})$ \\
\hline ADIS & 0.10 & 3.14 \\
ALBH & 10.00 & 2.20 \\
AUCK & 5.50 & -3.29 \\
BOR1 & 6.24 & 4.66 \\
BRST & 204.31 & 54.58 \\
BUCU & 9.70 & 9.09 \\
COCO & 0.40 & -4.78 \\
DAEJ & 0.00 & -0.77 \\
DUBO & 10.00 & 2.15 \\
GOPE & 11.14 & 5.73 \\
HERT & 0.00 & 2.53 \\
HOFN & 3.19 & 4.92 \\
KIR0 & 7.10 & 12.45 \\
MATE & 10.10 & 5.85 \\
NKLG & 304.30 & 64.74 \\
NTUS & 7.76 & -75.81 \\
ONSA & 99.50 & 26.03 \\
POTS & 12.06 & 6.11 \\
REYK & 5.70 & 4.78 \\
THTI & 104.70 & 13.67 \\
VIS0 & 7.10 & 5.05 \\
WTZR & 7.10 & 6.73 \\
\hline & &
\end{tabular}

fixed solutions after sufficiently long times of convergence. However, they demonstrated the usefulness of ambiguity fixing for the rapid re-initialization of an RT-PPP estimation system (e.g., after an interruption in the data stream).

To verify the claimed reason for the large bias in the PPP-Wizard solutions, i.e., the lack of ARP eccentricity and PCO corrections, another processing experiment for a different 1-week long period using the PPP-Wizard was conducted in which the coordinates were corrected for ARP eccentricities and the PCO prior to processing. The $L_{1}$ and $L_{2}$ PCOs have been combined by using the ionospheric free linear combination, i.e.,

$\mathrm{PCO}_{L_{1}+L_{2}}=\frac{f_{1}^{2} \mathrm{PCO}_{L_{1}}-f_{2}^{2} \mathrm{PCO}_{L_{2}}}{f_{1}^{2}-f_{2}^{2}}$

where $f_{1}=1575.42 \mathrm{MHz}, f_{2}=1,227.60 \mathrm{MHZ}$, and $\mathrm{PCO}$ values are in millimeters.

Integer ambiguity fixing was also applied during this experiment. We name the PPP-Wizard solution from this new experiment as PWFX2. The RT-PPP ZTD estimates from PWFX2 were then compared with the corresponding IGFT estimates. The bias between IGFT and PWFX2 was found to be $2.33 \pm 2.76 \mathrm{~cm}$ (in contrast to $6.81 \pm 2.42 \mathrm{~cm}$ for IGFT-PWFL) with an RMS of $4.60 \mathrm{~cm}$ (in contrast to $14.96 \mathrm{~cm}$ for IGFT-PWFL). This implies that after 
Table 9 Statistics of comparison between GNSS-derived and RSbased ZTD

\begin{tabular}{|c|c|c|c|}
\hline $\begin{array}{l}\text { RT-PPP } \\
\text { Solution }\end{array}$ & $\begin{array}{l}\text { Mean }\left(\mathrm{ZTD}_{\mathrm{GNSS}^{-}}\right. \\
\left.\mathrm{ZTD}_{\mathrm{RS}}\right)(\mathrm{cm})\end{array}$ & $\begin{array}{l}\mathrm{STD}\left(\mathrm{ZTD}_{\mathrm{GNSS}^{-}}\right. \\
\left.\mathrm{ZTD}_{\mathrm{RS}}\right)(\mathrm{cm})\end{array}$ & $\begin{array}{l}\mathrm{RMS} \\
\left(\mathrm{ZTD}_{\mathrm{GNSS}^{-}}\right. \\
\left.\mathrm{ZTD}_{\mathrm{RS}}\right)(\mathrm{cm})\end{array}$ \\
\hline BN01 & 1.40 & 3.44 & 4.41 \\
\hline BN02 & 1.71 & 3.19 & 4.30 \\
\hline PWFX2 $^{\mathrm{a}}$ & 2.76 & 3.12 & 5.23 \\
\hline GN01 & 2.17 & 1.32 & 3.04 \\
\hline GN02 & 2.12 & 1.29 & 3.01 \\
\hline
\end{tabular}

a The solution after application of eccentricity and PCO corrections and ambiguity resolution

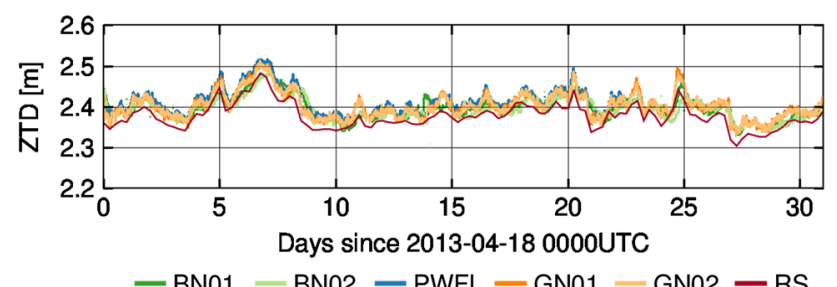

Fig. 3 RT-PPP ZTD estimates and RS-based ZTD for station HERT

applying the ARP eccentricity and PCO corrections to the a priori coordinates, the mean bias between the ZTD estimates from PPP-Wizard and IGFT has been reduced by approximately $66 \%$ and the RMS of this bias has been reduced by approximately $70 \%$.

\section{External evaluation}

The statistics from the comparison of GNSS-derived ZTD and RS-based ZTD are summarized in Table 9. In terms of standard deviation, the G-Nut/Tefnut solutions (GN01 and GN02) show the best agreement to the RS-based ZTD, whereas in terms of the mean bias, BNC2.7 solutions (BN01 and BN02) show the best agreement to the RSbased ZTD. The BNC2.7 solutions show mean biases between 1 and $2 \mathrm{~cm}$, whereas G-Nut/Tefnut and PPPWizard solutions show mean biases between 2 and $3 \mathrm{~cm}$ with the RS-based ZTD. In contrast to the comparison with IGFT, the mean bias of the BN01 solution is lower than that of the G-Nut/Tefnut solutions, which is because of the fact that the statistics of the RS comparisons are based on the five selected stations (unlike 22 stations in the case of IGFT comparisons) and the biases are station specific. Figure 3 shows the time series of GNSS-derived and RSbased ZTD estimates for the station HERT as an example. It can be seen that all the time series follow the same pattern, and both the GNSS-derived and RS-based ZTD are sensitive to the variations in a similar fashion. This is also the case for the other 4 stations not shown in Fig. 3. The

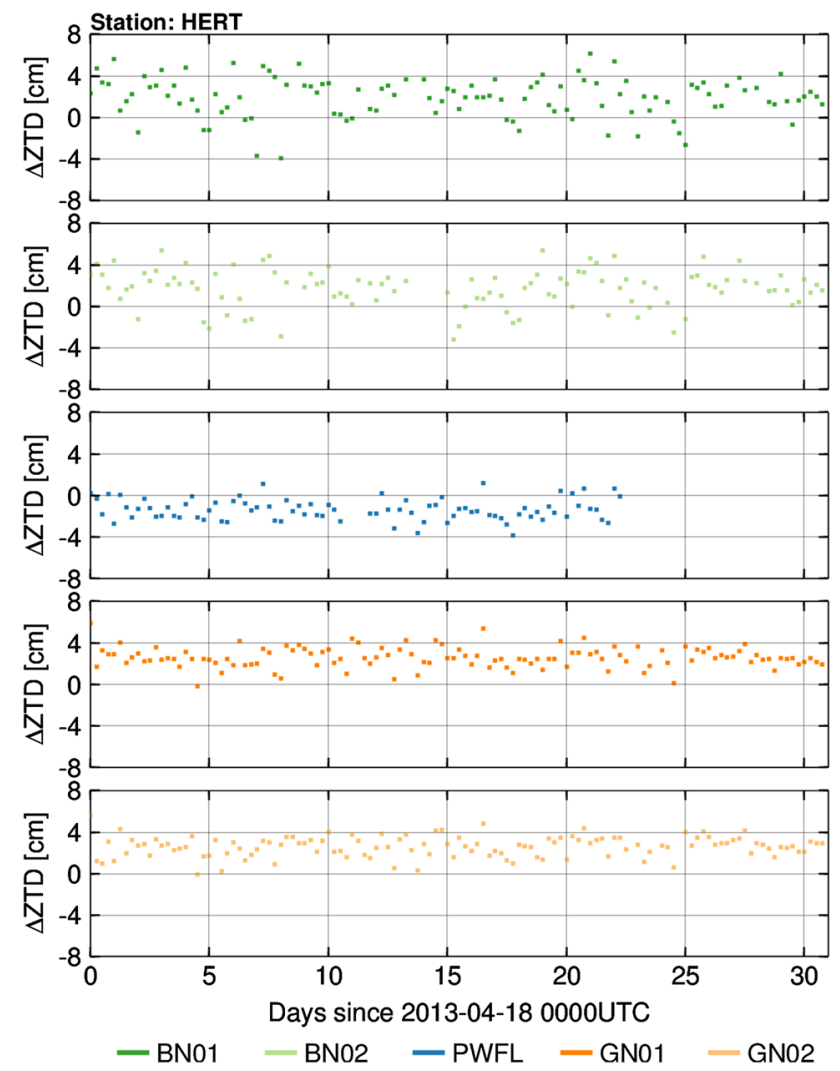

Fig. 4 Difference of RT-PPP ZTD and RS-based ZTD estimates for station HERT

time series of the difference between the RT-PPP ZTD solutions and the RS-based ZTD for the station HERT are show in Fig. 4.

\section{Discussion}

The COST Action 716: Exploitation of Ground-Based GPS for Climate and NWP Analysis, which was a demonstration project to study the potential of ZTD products from ground-based GPS networks for NWP and climate monitoring, specified various user requirements (Offiler 2010) for GNSS meteorology, which define threshold and target values on timeliness, accuracy and resolution, etc., of ZTD and IWV estimates for use in NWP nowcasting and climate monitoring. These requirements are widely accepted for quality control during operational use. Table 10 summarizes the current user requirements for NWP nowcasting; however, during the new COST Action ES1206 (GNSS4SWEC), these requirements will be revised. The typical value of the dimensionless conversion factor $\mathrm{Q}$ (Askne and Nordius 1987) used for the conversion of ZWD to IWV is approximately 6 , and therefore, $1 \mathrm{~kg} / \mathrm{m}^{2}$ of IWV is equivalent to about $6 \mathrm{~mm}$ of ZTD (Glowacki et al. 
Table 10 User requirements for GNSS meteorology (NWP nowcasting)

\begin{tabular}{lll}
\hline Parameter & Target & Threshold \\
\hline Horizontal domain & Europe to National & \\
Repetition cycle & $5 \mathrm{~min}$ & $1 \mathrm{~h}$ \\
Integration time & $\mathrm{MIN}(5 \mathrm{~min}$, rep cycle $)$ \\
Relative accuracy & $1 \mathrm{~kg} / \mathrm{m}^{2}$ & $5 \mathrm{~kg} / \mathrm{m}^{2}$ \\
Timeliness & $5 \mathrm{~min}$ & $30 \mathrm{~min}$ \\
\hline
\end{tabular}

2006). Using this equivalence, the accuracy requirements for IWV can be translated into their equivalent for ZTD, which are $6 \mathrm{~mm}(0.6 \mathrm{~cm})$ target and $30 \mathrm{~mm}(3 \mathrm{~cm})$ threshold values. Considering the IGFT as the truth and the RMS of the bias of each solution from IGFT as a measure of its relative accuracy, the obtained RT-PPP ZTD solutions can be compared with these requirements. Table 11 shows this comparison for each RT solution generated in this study.

It can be seen from Table 11 that BN02, GN01 and GN02 meet the threshold requirement for relative accuracy, whereas BN01 and PWFL exceed the threshold. Although the application of the ARP eccentricity and PCO corrections on the coordinates prior to processing has improved the relative accuracy of the PPP-Wizard solution, it currently exceeds the threshold requirements for NWP nowcasting.

A similar comparison (not shown) with these user requirements conducted by considering the RMS of the difference between GNSS-derived ZTD and RS-based ZTD as a measure of relative accuracy yields that only the two G-Nut/Tefnut solutions (GN01 and GN02) meet the threshold requirements, whereas the others exceed the threshold. However, the RS-based ZTD also has an uncertainty, and it is possible that it has a bias due to inaccurate height corrections.

\section{Conclusions}

The suitability of RT-PPP ZTD estimates from three different software packages for operational meteorology was assessed through a comparative analysis using the IGS final troposphere product and RS data as references. In terms of standard deviation, it was seen that the solutions from the G-Nut/Tefnut software library achieves the best agreement with these. The solutions from BNC2.7 are the next closest to the references. Among the BNC2.7 solutions, lower biases have been found for the solutions computed using the correction stream containing a Kalman Filter combination (IGS02) rather than the one computed using a single-epoch solution correction stream (IGS01). The ambiguity float solution from the PPP-Wizard has the largest bias to the
Table 11 Comparison of RT relative accuracies to user requirements of GNSS meteorology

\begin{tabular}{|c|c|c|c|c|}
\hline $\begin{array}{l}\text { RT-PPP } \\
\text { Solution }\end{array}$ & $\begin{array}{l}\mathrm{ZTD} \\
\text { relative } \\
\text { accuracy } \\
(\mathrm{cm})\end{array}$ & $\begin{array}{l}\text { Difference } \\
\text { from required } \\
\text { target }(\mathrm{cm})\end{array}$ & $\begin{array}{l}\text { Difference } \\
\text { from required } \\
\text { threshold }(\mathrm{cm})\end{array}$ & Remarks \\
\hline BN01 & 6.04 & 5.44 & 3.04 & $\begin{array}{l}\text { Exceeds } \\
\text { the } \\
\text { threshold }\end{array}$ \\
\hline BN02 & 2.92 & 2.32 & -0.08 & $\begin{array}{l}\text { Meets the } \\
\text { threshold }\end{array}$ \\
\hline PWFL & 14.96 & 14.36 & 11.96 & $\begin{array}{l}\text { Exceeds } \\
\text { the } \\
\text { threshold }\end{array}$ \\
\hline GN01 & 1.43 & 0.83 & -1.58 & $\begin{array}{l}\text { Meets the } \\
\text { threshold }\end{array}$ \\
\hline GN02 & 1.38 & 0.78 & -1.62 & $\begin{array}{l}\text { Meets the } \\
\text { threshold }\end{array}$ \\
\hline PWFX2 & 4.64 & 4.04 & 1.64 & $\begin{array}{l}\text { Exceeds } \\
\text { the } \\
\text { threshold }\end{array}$ \\
\hline
\end{tabular}

IGFT because of the fact that it currently does not apply receiver ARP eccentricity and PCO corrections during processing. However, the application of ARP eccentricity and PCO corrections on the coordinates prior to processing leads to a $66 \%$ reduction in this bias. Integer ambiguity resolution using the PPP-Wizard seems to have a millimeter-level effect on the RT-PPP ZTD estimates.

The RT-PPP ZTD solutions were compared with the established user requirements for NWP nowcasting by using RMS bias to IGFT as a measure of relative accuracy. It was found that GN01, GN02, and BN02 fulfill the threshold requirements on ZTD accuracy, whereas BN01, and PWFL, PWFX (and PWFX2) exceed this threshold. The RT-PPP ZTD solutions were also compared with RSbased ZTD, and an agreement of $1-3 \mathrm{~cm}$ in terms of bias and $1-4 \mathrm{~cm}$ in terms of standard deviation was found between the two. Furthermore, the comparison with the user requirements was repeated by using the RMS bias between GNSS-derived ZTD and RS-based ZTD as a measure of relative accuracy, and it showed that only the two G-Nut/Tefnut solutions (GN01 and GN02) meet the threshold requirements, whereas the BNC2.7 and PPPWizard solutions, without the implementation of precise bias models in the software, exceed the threshold. However, the implementation of precise bias models such as receiver antenna PCV, ocean tide loading and higher-order ionospheric corrections in these software packages can enhance their suitability for NWP nowcasting.

Acknowledgments This project is funded by the Fonds National de la Recherche, Luxembourg (Reference No. 1090247). The work at GOP was funded by the Czech Science Foundation (Project No. P209/ 12/2207). The cooperation was supported by the COST Action 
ES1206. We are thankful to BKG for the BNC 2.7 software and the EUREF and IGS communities for GNSS data and products. We also thank two anonymous reviewers for their valuable feedback to improve this paper.

Open Access This article is distributed under the terms of the Creative Commons Attribution License which permits any use, distribution, and reproduction in any medium, provided the original author(s) and the source are credited.

\section{References}

Askne J, Nordius H (1987) Estimation of tropospheric delay for microwaves from surface weather data. Radio Sci 22:379-386

Benjamin SG, Jamison BD, Moninger WR, Sahm SR, Schwartz BE, Schlatter TW (2010) Relative short-range forecast impact from aircraft, profiler, radiosonde, VAD, GPS-PW, METAR and mesonet observations via the RUC hourly assimilation cycle. Mon Weather Rev 138(4):1319-1343

Bennitt G, Levick T (2011) The impact of assimilating zenith total delay measurements from ground-based GNSS receivers in the Met Office numerical weather prediction UK model. Geophys Res Abstr vol 13, EGU2011-6705

Bevis M, Businger S, Chiswell S, Herring TA, Anthes RA, Rocken C, Ware RH (1994) GPS meteorology: mapping zenith wet delays onto precipitable water. J Appl Meteorol 33(3):379-386

Brian CA, Clifford FM, Kirby C, Brad C (2014) Comparison of surface wind and temperature analyses from an ensemble Kalman filter and the NWS real-time mesoscale analysis system. Weather Forecast 29:1058-1075

Byram S, Hackman C, Slabinski V, Tracey J (2011) Computation of a high-precision GPS-based troposphere product by the USNO. In: Proceedings of ION GNSS 2011, Institute of Navigation, Portland, Oregon, USA, pp 572-578

Byun SH, Bar-Sever YE (2009) A new type of troposphere zenith path delay product of the international GNSS Service. J Geodesy 83(3-4):1-7

Caissy M, Agrotis L, Weber G, Hernandez-Pajares M, Hugentobler U (2012) The international GNSS real-time service. GPS World 23(6):p52

Dach R, Hugentobler U, Fridez P, Meindl M (eds) (2007) Bernese GPS software version 5.0, 612, Astronomical Institute, University of Bern

De Haan S (2011) Impact of GPS ZTD on rainfall estimates in an hourly update cycle of a numerical weather prediction model. Geophys Res Abstr vol 13, EGU2011-4222

Douša J (2012) The impact of errors in predicted GPS orbits on zenith troposphere delay estimation. GPS Solut 14(3):229-239

Douša J, Elias M (2014) An improved model for calculating tropospheric wet delay. Geophys Res Lett 41:4389-4397. doi:10.1002/2014GL060271

Douša J, Vaclavovic P (2014) Real-time zenith tropospheric delays in support of numerical weather prediction applications. Adv Space Res 53(9):1347-1358

Dow JM, Neilan RE, Rizos C (2009) The international GNSS service in a changing landscape of global navigation satellite systems. J Geodesy 83(3-4):191-198

Elgered G (2001) An overview of COST Action 716: exploitation of ground-based GPS for climate and numerical weather prediction applications. Phys Chem Earth Part A 26(6-8):399-404

Fritsche M, Dietrich R, Knöfel C, Rülke A, Vey S (2005) Impact of higher-order ionospheric terms on GPS estimates. Geophys Res Lett 32:L23311. doi:10.1029/2005GL024342
Geng J, Teferle FN, Shi C, Meng X, Dodson AH, Liu J (2009) Ambiguity resolution in precise point positioning with hourly data. GPS Solut 13(4):263-270

Geng J, Meng X, Dodson AH, Teferle FN (2010) Integer ambiguity resolution in precise point positioning: method comparison. J Geodesy 84(9):569-581

Glowacki TJ, Penna NT, Bourke WP (2006) Validation of GPS-based estimates of integrated water vapour for the Australian region and identification of diurnal variability. Aust Meteorol Mag 55:131-148

Gutman SI, Sahm SR, Benjamin SG, Schwartz BE, Holub KL, Stewart JQ, Smith TL (2004) Rapid retrieval and assimilation of ground based GPS precipitable water observations at the NOAA forecast systems laboratory: impact on weather forecasts. J Meteorol Soc Jpn 82(1B):351-360

Gyori G, Douša J (2013) GOP-TropDB development for tropospheric product evaluation and monitoring-design, functionality and initial results. In: Rizos C, Willis P (eds), IAG symposia series, vol 143. Springer (accepted for publication)

Hill EM, Davis JL, Elósegui P, Wernicke BP, Malikowski E, Niemi NA (2009) Characterization of site-specific GPS errors using a short-baseline network of braced monuments at Yucca Mountain, southern Nevada. J Geophys Res 114:B11402. doi:10.1029/ 2008JB006027

Huang XY et al (2003) TOUGH: targeting optimal use of GPS humidity measurements in meteorology. In: Proceedings of international workshop on GPS meteorology, Tsukuba, Japan, 14-17 January 2003

Iwabuchi T, Naito I, Mannoji N (2000) A comparison of global positioning system retrieved precipitable water vapor with the numerical weather prediction analysis data over the Japanese Islands. J Geophys Res 105(4573-4585):C2000

Jones J, Guerova G, Dousa J, de Haan S, Bock O, Dick G, Pottiaux E, Pacione R (2014) COST Action ES1206 : advanced global navigation satellite systems tropospheric products for monitoring severe weather events and climate (GNSS4SWEC). Geophys Res Abstr vol 16, EGU2014-14097

Lagler K, Schindelegger M, Boehm J, Krásná H, Nilsson T (2013) GPT2: empirical slant delay model for radio space geodetic techniques. Geophys Res Lett 40:1069-1073. doi:10.1002/grl. 50288

Laurichesse D (2011) The CNES real-time PPP with undifferenced integer ambiguity resolution demonstrator. In: Proceedings of ION GNSS 2011, Institute of Navigation, Portland, OR, 654-662

Laurichesse D, Mercier F, Berthias JP, Broca P, Cerri L (2009) Integer ambiguity resolution on undifferenced GPS phase measurements and its application to PPP and satellite precise orbit determination. Navigation 56(2):135-149

Li X, Dick G, Ge M, Heise S, Wickert J, Bender M (2014) Real-time GPS sensing of atmospheric water vapor: precise point positioning with orbit, clock, and phase delay corrections, Geophys Res Lett, 41. doi:10.1002/2013GL058721

Loyer S, Perosanz F, Mercier F, Capdeville H, Marty J-C (2012) Zero-difference GPS ambiguity resolution at CNES-CLS IGS analysis center. J Geodesy 86(11):991-1003

NERC Centres for Atmospheric Science-British Atmospheric Data Centre (2006) http://badc.nerc.ac.uk/view/badc.nerc.ac.uk_ ATOM_dataent_GLOBRADS

Ning T (2012) GPS meteorology: with focus on climate applications, $\mathrm{PhD}$ thesis, Chalmers University of Technology, ISBN 978-917385-675-1

Offiler D (2010) Product requirements document version 1.0-21 December 2010. EIG EUMETNET GNSS Water Vapour Programme (E-GVAP-II) 
Park C-G, Roh K-M, Cho J (2012) Radiosonde sensors bias in precipitable water vapor from comparisons with global positioning system measurements. J Astron Space Sci 29(3):295-303

Shi J, Gao Y (2012) Improvement of PPP-inferred tropospheric estimates by integer ambiguity resolution. Adv Space Res 50(10):1374-1382

Smith TL, Benjamin SG, Gutman SI, Sahm SR (2007) Forecast impact from assimilation of GPS-IPW observations into the rapid update cycle. Mon Weather Rev 135(8):2914-2930

Thomas ID, King MA, Clarke PJ, Penna NT (2011) Precipitable water vapor estimates from homogeneously reprocessed GPS data: an intertechnique comparison in Antarctica. J Geophys Res, 116. doi:10.1029/2010JD013889

Tregoning P, Herring TA (2006) Impact of a priori zenith hydrostatic delay errors on GPS estimates of station heights and zenith total delays. Geophys Res Lett 33:L23303. doi:10.1029/ 2006GL027706

Václavovic P, Douša J, Gyori G (2013) G-Nut software library-state of development and first results. Acta Geodyn Geomater 10(172) (in print)

Vedel H, Huang X-Y, Haase J, Ge M, Calais E (2004) Impact of GPS zenith tropospheric delay data on precipitation forecasts in Mediterranean France and Spain. Geophys Res Lett 31:L02102. doi:10.1029/2003GL017715

Vedel H, de Haan S, Jones J, Bennitt G, Offiler D (2013) E-GVAP third phase. Geophys Res Abstr vol 15, EGU2013-10919

Weber G, Mervart L (2012) BKG Ntrip Client (BNC) version 2.7 manual, federal agency for cartography and geodesy, Frankfurt, Germany

Weber G, Dettmering D, Gebhard H (2006) Networked transport of RTCM via internet protocol (NTRIP). IAG Symp Ser 128:60-64

Wübbena G, Schmitz M, Bagge A (2005) PPP-RTK: precise point positioning using state-space representation in RTK networks. In: Proceedings of ION GNSS 2005, Institute of Navigation, Portland, OR, pp 2584-2594

Yuan Y, Zhang K, Rohm W, Choy S, Norman R, Wang C-S (2014) Real-time retrieval of precipitable water vapor from GPS precise point positioning. J Geophys Res Atmos, 119. doi:10.1002/ 2014JD021486

Zumberge JF, Heftin MB, Jefferson DC, Watkins MM (1997) Precise point positioning for the efficient and robust analysis of GPS data from large networks. J Geophys Res 102(B3):5005-5017

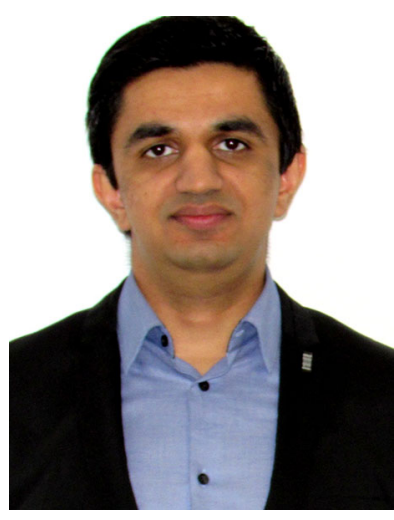

Furqan Ahmed is a $\mathrm{PhD}$ candidate at the University of Luxembourg. He obtained his MSc degree (2010) in Radio and Space Science from Chalmers University of Technology, Sweden and BS degree (2008) in Telecommunication Engineering from National University of Computer and Emerging Sciences, Pakistan. His current research focuses on the use of GNSS observations in operational meteorology and climate monitoring.

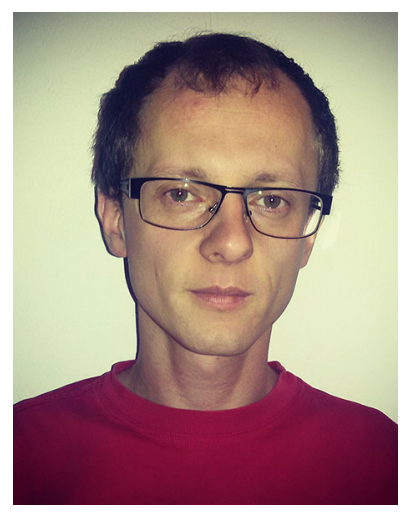

Pavel Václavovic is currently a $\mathrm{PhD}$ student at the Czech Technical University in Prague. He received his $\mathrm{MSc}$ degree in geodesy at the same university in 2009. Since 2011, he is working at the Geodetic Observatory Pecny (GOP). His main research is focused on algorithms for Precise Point Positioning. He is coauthor of the G-Nut software library and various derived enduser applications.

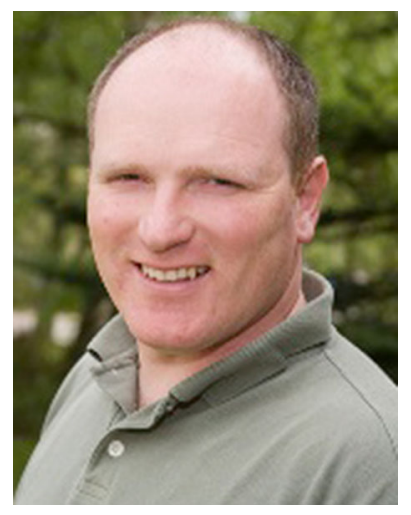

modelling of time series.

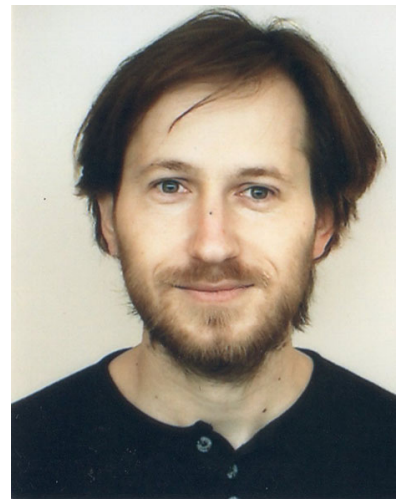
is a core developer of the G-Nut software library and various derived end-user applications. 


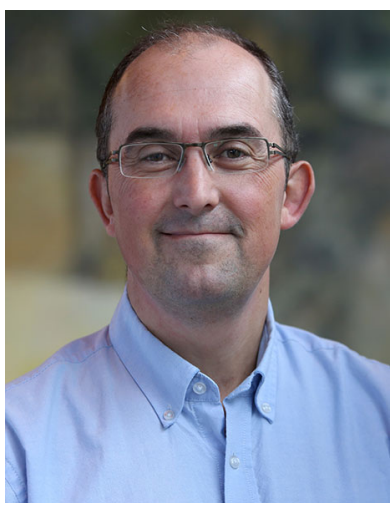

Richard Bingley has a BEng and $\mathrm{PhD}$ from the University of Nottingham, UK. His research interests are focussed on the development of GNSS techniques for monitoring vertical land movements in relation to sea level, and measuring integrated water vapour as an input to meteorology and climate studies. He is also Head of the NERC British Isles continuous GNSS Facility (BIGF).

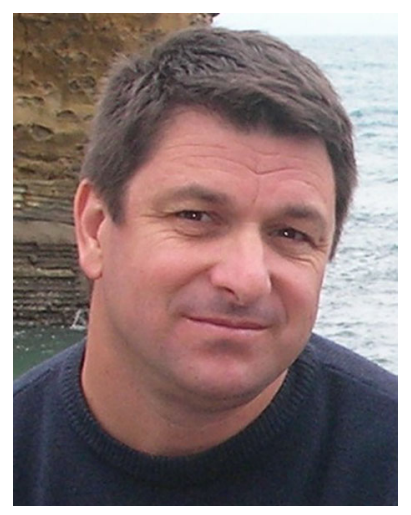

Denis Laurichesse received his engineering degree and an advanced study diploma (D.E.A) from I.N.S.A. (National Institute for Applied Sciences), in 1988, in Toulouse, France. $\mathrm{He}$ is working at C.N.E.S (The French Space Agency) since 1992 in the Spaceflight Dynamics Department, responsible for the development of the on-board GNSS Diogene navigator. $\mathrm{He}$ is involved in the performance assessment of EGNOS and Galileo systems. He specialises in navigation, satellite precise orbit determination and GNNS basedsystems. 